\title{
Globally consistent reef size spectra integrating fishes and invertebrates
}

\author{
Freddie J. Heather ${ }^{1, *}$, Julia L. Blanchard ${ }^{1}$, Graham J. Edgar ${ }^{1}$, Rowan \\ Trebilco $^{1,2}$, and Rick D. Stuart-Smith ${ }^{1}$ \\ ${ }^{1}$ Institute for Marine and Antarctic Studies, University of Tasmania, 20 Castray Esplanade, \\ Battery Point, Hobart, TAS 7004, Australia \\ ${ }^{2}$ CSIRO Oceans and Atmosphere, Battery Point, Hobart, TAS 7004, Australia
}

Short title: Globally consistent reef size spectra

Author emails: freddieheather@gmail.com*, julia.blanchard@utas.edu.au, g.edgar@utas.edu.au, rowan.trebilco@csiro.au,rick.stuartsmith@utas.edu.au

Keywords: coastal, size distribution, fish, trophic pathways, community, benthic, macroecology, biomass equivalence rule, size spectrum

Statement of authorship: FJH designed the analysis, analysed the data and led the writing of the manuscript. All authors contributed to critical feedback, interpretation, and substantial revisions of the paper.

Data accessibility statement: Code for the analysis, and to recreate all figures, is available at https://github.com/FreddieJH/inverts_size_spec. Most of the data used in this study are publicly available at https://reeflifesurvey.com/survey-data/, although body size information are unavailable until public release of the redeveloped database in mid-2021. In the interim, these data can be provided upon request by contacting enquiries@reeflifesurvey.com.

Article type: Letters

Abstract word count: 143

Main text word count: 2778

Reference count: 72

Figure $\backslash$ Table $\backslash$ Text box count: $4 \backslash 0 \backslash 0$

Corresponding author: Freddie Heather; IMAS Taroona, 15-21 Nubeena Cres, Taroona TAS 7053, Australia; freddieheather@gmail.com 


\section{Abstract}

2 The frequency distribution of individual body sizes in animal communities (i.e. the size 3 spectrum) provides powerful insights for understanding the energy flux through food webs.

4 However, studies of size spectra in rocky and coral reef communities typically focus only

5 on fishes or invertebrates due to taxonomic and data constraints, and consequently ignore 6 energy pathways involving the full range of macroscopic consumer taxa. We analyse size spec7 tra with co-located fish and mobile macroinvertebrate data from 3,369 reef sites worldwide, 8 specifically focusing on how the addition of invertebrate data alters patterns. The inclusion 9 of invertebrates steepens the size spectrum, more so in temperate regions, resulting in a 10 consistent size spectrum slope across latitudes, and bringing slopes closer to theoretical ex11 pectations based on energy flow through the system. These results highlight the importance 12 of understanding contributions of both invertebrates and fishes to reef food webs worldwide. 


\section{${ }_{13}$ Introduction}

${ }_{14}$ Body size is arguably the most important single factor determining an individual's vital 15 rates and how it interacts with its environment (Brown et al., 2004). Body size distributions therefore provide rich insights into size-dependent relationships between animals and underlying energy flow of communities. One such distribution links individual body size and abundance in a community (the community size spectrum). This relationship has been extensively studied in both marine and terrestrial realms (e.g. Reuman et al., 2008), following early conjectures of a "biomass equivalence rule": that biomass is approximately equal across logarithmic size bins spanning sizes of the smallest to the largest creatures Ghilarov, 1944; Sheldon et al., 1972). This results in a negative power-law relationship between abundance concentration $(N)$ and body size $(M)\left(\right.$ Andersen and Beyer, 2006), $N \propto M^{\lambda}$, where $\lambda \approx-2$. Because of the important information concerning system-wide energy movements (Brown and Gillooly, 2003; Trebilco et al., 2013), methods used to estimate the power law exponent have been extensively evaluated in the literature (White et al., 2008; Edwards et al., 2017). ․ Although remarkable consistencies in empirical size spectra have been observed Sprules et al., 2016), substantial deviations can also occur. These deviations provide important information about ecosystem structure and perturbations. For example, the selective removal of larger individuals through fishing has been shown to steepen the negative slope of the size spectrum in both pelagic (Daan et al., 2005; Pope and Knights, 1982, Blanchard et al., 2005) and reef ecosystems (Dulvy et al., 2004; Graham et al., 2005; Wilson et al., 2010; Robinson et al., 2017). By contrast, seasonal competition for resources (Edgar, 1994) and energy subsidies from outside the reef ecosystem (Trebilco et al., 2013, 2016; Morais and Bellwood, 2019) can potentially result in shallower size spectra, while habitat complexity can cause deviations of the size spectra from the expected power law (Rogers et al., 2014). For a community of individuals feeding on a common resource, i.e. at a single trophic level, such as herbivorous fishes (Robinson et al., 2016), abundance may also scale less steeply with body size, following the allometric scaling of body size with metabolic rate and energetic equivalence Damuth, 
40 1981; Kleiber, 1932; Nee et al., 1991). However, most aquatic communities are comprised 41 of a trophic chain or web, whereby individuals feed upon one another as well as the basal 42 resource. Consequently, due to inefficiencies in the transfer of energy between trophic levels 43 (Lindeman, 1942), fewer individuals can be sustained when feeding at higher trophic levels. 44 Given the strong relationship between an individual's size and its trophic position (Jennings 45 et al., 2001), this is consistent with fewer large-bodied individuals in a community arising 46 from individuals feeding in a size-based way (i.e. a food chain or web) (Brown and Gillooly, 47 2003; Jennings and Mackinson, 2003; Trebilco et al., 2013; Andersen, 2019). Although the 48 general pattern of declining abundance with body size holds in many places, particularly at very large spatial scales, there has been no global test of the "biomass equivalence rule" at the community scale for reefs or any other large system (Polishchuk and Blanchard, 2019).

Global datasets available to test the "biomass equivalence rule" for marine systems have been previously lacking. The Reef Life Survey (RLS) program has quantified the abundance and size distribution of all conspicuous species on reef habitats globally (Edgar and StuartSmith, 2014) and provides the best available means for exploring biomass equivalence at this scale. It is the largest single database, terrestrial or marine, in terms of its taxonomic, spatial and temporal coverage with a basis of standardized quantitative methods. The high resolution yet global coverage of the data enables us to investigate size spectra at varying spatial scales.

Another challenge relates to the major missing component of reef community size spectra: benthic invertebrates. Whilst most previous empirical work on reef size spectra has focused solely on fish communities, large mobile benthic invertebrates can play fundamental roles in reef ecosystems, even to the point of dominating the animal biomass present. For example, in some temperate reefs, we observed communities in which over $90 \%$ of individuals $>1 \mathrm{~cm}$ body size, were invertebrates (see also Edgar et al., 2017). Furthermore, considerable overlap exists in resource use between fishes and invertebrates, with overlap in the diets of many fishes and invertebrates, and many fish predators relying heavily on invertebrate prey (i.e. fishes and 
67

invertebrates do not necessarily occupy separate energy pathways)(Barneche et al., 2014). As such, to better understand the size structure of whole reef communities and food webs that are not artificially constrained by taxonomic group, data on both fishes and invertebrates are needed. Several previous studies have recognized the potential importance of invertebrates in reef size spectra (e.g. Donovan et al. 2018), but body size data were lacking. Here, we use invertebrate body size data to test the "biomass equivalence rule" for size spectra of reef communities, comparing fish-only data and fish and invertebrate data for the same sites globally.

We hypothesize that: 1) The inclusion of invertebrates will change the slope (i.e. exponent) of the community size spectrum (Figure 1). If invertebrates are relatively smaller bodied than their fish counterparts in a community (e.g. Figure 1A), we would expect their inclusion in the size spectrum to have a steepening effect (Figure 1B). Likewise, if invertebrates are relatively larger bodied than the fishes in the community (e.g. Figure 1C), we would expect a shallowing effect when they are included (Figure 1D). This also might correspond to a situation where herbivorous or detritivorous invertebrates occupy a single trophic level, which would result in shallower slopes (Dinmore and Jennings, 2004, Maxwell and Jennings, 2006). We further hypothesize that: 2) This invertebrate inclusion effect will be greater in temperate communities compared to tropical communities due to a relatively greater proportion of invertebrates in temperate reefs (Edgar et al., 2017). 3) The broad geographic span and fine transect-level grain allows us to consider multiple spatial scales, and thereby test our third hypothesis; spatial scale of sampling contributes to variation around slope estimates. A $\lambda$ of -2 is expected in the absence of human impacts, such as fishing. Because few reefs worldwide are beyond the reach of fishers, we expect to find a steeper (more negative) slope overall. This study provides improved understanding on the variability of reef size spectrum slopes globally, which is crucial for the development of size spectra as indicators for reef ecosystem health (e.g. Nash and Graham, 2016; Trebilco et al., 2016; Zgliczynski and Sandin, 2017, Morais et al., 2020a). 


\section{${ }_{94}$ Methods}

${ }_{95}$ Survey data

96 Applying the RLS protocol (available at https://www.reeflifesurvey.com/), trained divers ${ }_{97}$ swim along a $50 \mathrm{~m}$ transect and identify to species level the fishes and invertebrates they encounter (Edgar and Stuart-Smith, 2014). A single survey $(n=11936$ surveys $)$ consists of two separate methods undertaken on the same transect line. Method 1 involves recording any fish species ( $n=2608$ species) within $5 \mathrm{~m}$ wide blocks either side of the line, whilst method 2 involves searching along the bottom, underneath kelp and in cracks in $1 \mathrm{~m}$ wide blocks either side of the line, recording invertebrates $(n=1184$ species $)$ and cryptic fishes $(n=951$ species). Abundance of each species within the defined block area is counted directly or estimated when necessary for highly abundant species. Size is estimated for all fishes, and by experienced biologists for invertebrates at some sites. Animals are estimated to belong to one of 13 size categories: 2.5, 5, 7.5, 10, 12.5, 15, 20, 25, 30, 35, 40, 50, and 62.5cm. Lengths greater than $62.5 \mathrm{~cm}$ are estimated to the nearest $12.5 \mathrm{~cm}$. For a full description of the survey methods, see RLS (2020). Abundance from method 2 records were standardized to the equivalent area covered by method 1 by multiplying abundance by five, standardizing all records as densities per $500 m^{2}$. A site $(n=3369$ sites) usually contained multiple surveys undertaken along at least two depths on the same day. Sites are nested in 'locations', which are nested within ecoregions ( $n=91$ ecoregions), as defined by the Marine Ecoregions of the World (Spalding et al., 2007).

\section{Estimation of invertebrate body length distributions}

All invertebrates encountered on surveys were identified to species level (or the highest taxonomic resolution possible) and counted within $1 \mathrm{~m}$ wide blocks either side of each $50 \mathrm{~m}$ transect line surveyed for fishes. At a small subset of surveys, body length of the invertebrates was estimated or measured. Species body length distributions with sufficient observations $(n>10$ 
per species, spanning a sufficient range of body length bins for distribution fitting) were therefore available for only 167 invertebrate species $(\approx 14 \%$ of total invertebrate species in the data) from seven taxonomic classes. For these species, individual body lengths were best described by a lognormal distribution, consistent with the body length distributions of the fish species and previous body length distribution literature (e.g. Blackburn and Gaston, 1994). For each species, we fitted a lognormal distribution to the body lengths using the 'fitdistrplus' package (Delignette-Muller and Dutang, 2015) in R (R Core Team, 2020). We then fitted two linear regression models estimating the two parameters of the lognormal distribution (mean and variance) using the asymptotic length of the species and its taxonomic class as predictor variables (Equations S1.2, S1.3). For the remaining species with only asymptotic length available, we were then able to reconstruct the lognormal body length distribution by estimating the two lognormal distribution parameters using these two regression models. Asymptotic sizes for all invertebrate species were obtained from SealifeBase (Palomares and Pauly, 2019).

\section{From body length to body mass}

Conversion to individual body mass distributions was achieved using published length-weight allometric relationships derived from SealifeBase (Palomares and Pauly, 2019) and FishBase (Froese and Pauly, 2010) and observed (where available) or estimated individual body length. For each species we calculated the asymptotic mass $\left(M_{\infty}\right)$ given asymptotic body length $\left(L_{\infty}\right)$ and the species' length-weight relationship. Where species-specific individual length-weight information was unavailable, body mass was estimated from one of two linear regression models: a class-level and an overall length-weight regression model (Supplementary material $\mathrm{S} 2)$.

To assess the effect of including invertebrates into the size spectrum on the estimation of the slope, all further analyses were carried out firstly with only fish species included, and secondly with invertebrates also included. Differences in the size spectrum slopes between 
these two analyses is referred to as the 'invertebrate inclusion effect' $(\Delta \lambda)$.

\section{Fitting the normalized abundance size spectrum}

Relationships between $N$ and $M$ are generally estimated from a linear regression of binned size data on a log-log scale Newman (2005). Size spectrum analyses often 'normalize' the $\mathrm{y}$-axis by dividing the abundance within each mass bin by the actual width of the $\mathrm{x}$-axis bin to account for varying bin widths. This normalization procedure has the effect of reducing the size spectrum slope by 1 and results in the slope being comparable with the power law exponent $\lambda$. Here we use the slope of the normalized abundance size spectrum to estimate the exponent $\lambda$. We chose a linear regression method over a maximum likelihood estimation of the exponent (see Edwards et al., 2017), due to the simplicity of incorporating the spatiallyhierarchical nature of the data (sites nested within ecoregions).

For each survey, individuals were binned into $\log _{2}$ mass bins, and the abundance within each bin calculated as the number of individuals in each bin. Ackerman and Bellwood (2000) found that the abundances of $75 \%$ of fish smaller than $5 \mathrm{~cm}$ were underestimated in reef visual census data. To avoid biases associated with under-sampling of small individuals, we applied a lower bound cut-off of $32 \mathrm{~g}$ body mass, which represented the modal $\log _{2}$ mass bin (Supplementary material S3, see also Ackerman et al., 2004). Abundances were divided by 500 to obtain abundance per $m^{2}$.

We normalized the abundance by dividing by the width of the logarithmic mass bin (Supplementary material S4). We then fitted linear mixed effects models of $\log _{2}$ abundance $(N)$ as a function of the $\log _{2}$ mass bin mid $(M)$ and with ecoregion $(e)$ and site $(s)$ as random effects, both having a random slope and intercept, and with site nested within ecoregion (Equation 1).

$$
\log _{2}(N)=\beta_{0}+u_{0, e}+u_{0, s \mid e}+\left(\beta_{1}+u_{1, e}+u_{1, s \mid e}\right) \cdot \log _{2}(M)+\epsilon
$$

where, $u_{0, e}, u_{0, s \mid e}, u_{1, e}$, and $u_{1, s \mid e}$ are normally distributed random effects, and where 


\section{${ }_{175}$ Results}

$\beta_{1}$ represents the overall (global-level) slope, $u_{1, e}$ is the ecoregion-level variation and $u_{1, s \mid e}$ the site level variation (given the ecoregion variation) in the slope estimates of the model (Supplementary material S4). Linear mixed models were fitted using the lme4 package (Bates et al., 2015) in $\mathrm{R}(\mathrm{R}$ Core Team, 2020). Confidence intervals around the overall slope estimate were estimated using the Wald method in the 'confint' function of the lme4 package (Bates et al., 2015).

For fish-only communities, we estimated the overall mean site-level slope of the normalized abundance size spectrum $(\lambda)$ as $-1.88( \pm 0.06,95 \%$ CI $)$. The inclusion of invertebrates steepened (i.e. decreased) $\lambda$ from -1.88 to $-2.04( \pm 0.06,95 \%$ CI)(Figure 2, One sample t-test: $\overline{\Delta \lambda}=-0.07, d f=3371, p<0.001)$.

Absolute latitude explained $13 \%$ of the variation in the invertebrate inclusion effect $(\Delta \lambda)$, with a greater steepening at higher latitudes (linear regression model: $\Delta \lambda \sim \operatorname{abs}($ latitude); $R^{2}=13 \%, p<0.001$ )(Figure 3B, C). Slopes for fish-only communities were shallower at high latitudes, while slopes for the combined fish and invertebrate data were remarkably consistent across latitudes (Figure 3A)(see also S5). This greater steepening by invertebrate inclusion, in higher latitude regions was also observed in sites with the greatest protection from fishing pressure (see Supplementary material S6).

Variation in the slope estimates were explained at both the ecoregion and site (given the ecoregion) scales (Figure 4). More of the variation in the slope was evident across ecoregions (Combined community: $\sigma_{e}=0.25,14 \%$ total variation), than among sites within ecoregions (Combined community: $\sigma_{s} \mid e=0.17,9 \%$ of total variation). The total variation explained, across all sites and ecoregions, is the sum of these two variation components, and hence shows that variation declines with increasing spatial scale overall. 


\section{Discussion}

This study provides the first global test of the generality of the "biomass equivalence rule" for reef communities, analyzing size spectra of 3,369 reef communities worldwide. Our analyses resulted in three key findings: 1) The inclusion of invertebrates, as opposed to a purely fish-centric approach generally used previously, brought the global estimate of size spectrum slopes closer to the theoretical exponent of -2 , the value expected under the biomass equivalence rule; 2) The effect of including invertebrates was most marked for temperate reefs, where invertebrates contribute a substantial fraction of reef animal biomass; and 3) The contributions to variance in slope estimates were comparable at both the ecoregion (14\%) and site scales (9\%). Many studies of size spectra aggregate observations to larger spatial scales, whereas our work shows that accounting for hierarchical sampling at the local community scale is important for informing the overall processes driving estimates of size spectra as well as testing the generality of theoretical expectations.

Size spectrum theory, that encompasses detailed mechanistic models describing size-based feeding and physiological constraints (Andersen, 2019, Blanchard et al., 2017) to simple scaling theory that summarises these processes via transfer efficiency and predator prey mass ratios (Brown and Gillooly, 2003; Jennings and Mackinson, 2003) both predict normalized abundance size spectrum slopes of approximately -2 . However, many processes can affect both of these assumptions and could contribute to the variation around this theoretical value, even in the absence of fishing (Trebilco et al., 2016; Eddy et al., 2020). The empirical consistency of the size spectrum slope across many different aquatic ecosystems (Sprules et al., 2016), and sensitivity to the effects of impacts such as fishing (Shin et al., 2005; Petchey and Belgrano, 2010), has led to its proposed use as an ecological indicator of ecosystem health for reefs (Nash and Graham, 2016). However, its uptake for reefs has been hampered by lack of knowledge of an appropriate baseline, due to apparent discrepancies between the simplifying assumptions of size spectrum theory and lack of consistency across reef fish size spectra. Previous studies on local reef fish communities have shown slopes shallower than -2 (e.g. 
-1.13 to 1.95, Robinson et al., 2017; -1.75, Ackerman et al., 2004; -1.58 , Robinson et al., 2016), potentially due to energetic subsidies (Trebilco et al., 2013, 2016), relatively greater levels of herbivory (Steneck et al., 2017), or size-dependent habitat refugia (Rogers et al., 2014), but still within the range of slopes estimated here for fish-only communities. Although not all these studies specifically aimed to test theory related to energy flow, the exclusion of invertebrates in these studies would have likely changed the slopes found. On average globally, we found that the inclusion of invertebrates into the community size spectrum steepened $\lambda$ from -1.88 to $-2.04(\Delta \lambda=-0.16)$, closer to the value of -2 that would be expected according to the "biomass equivalence rule". All sites in this study are subject to varying levels of human disturbance (e.g. fishing), and therefore we might expect that in the absence of fishing pressure, reef communities would have shallower size spectra than this -2 estimate.

The effect of including invertebrates varied geographically, with a much greater effect at higher latitudes. At the highest latitudes considered here (approx. $60^{\circ} \mathrm{N}$ or S), fish-only size spectra had slopes that were more consistent with an inverted biomass pyramid (Trebilco et al., 2013), where biomass increases with body size and trophic level. The opposite was true for invertebrate-only size spectra, whereby the steepest slopes were observed at the highest latitude (Figure 3A). These two taxonomic groups, however, are not independent food web entities and interact through competition and predation. Combining these two groups into the size spectrum led to consistency in the slope across latitudes. The resultant pattern translates to an even distribution of log-log biomass across all body sizes and across latitudes, supporting previous conjectures of biomass equivalence holding from bacteria to whales and from the tropics to the poles (Sheldon et al., 1977; Kerr and Dickie, 2001). The latitudinal difference of including invertebrates is likely due to their dominance on temperate reefs, compared to more fish-dominated tropical reefs (Edgar et al., 2017). Whilst fishing pressure is non-random across the globe (Anticamara et al., 2011), it is unlikely to be the cause of the observed latitudinal patterns in the invertebrate inclusion effect, as we observe similar 
latitudinal patterns in sites within the most highly effective marine protected areas (Figure S6.1). Herbivores are also important on tropical reefs, and previous work has suggested that communities with a high biomass of herbivores, which do not feed according to size, should produce shallower size spectra (Robinson et al., 2017), as a result of being able to obtain relatively larger body sizes due to less energy lost through transfer efficiency (Brown and Gillooly, 2003). Larger-bodied herbivores also have the added advantage of reduced predation risk from gape-limited predators (e.g. Mumby, 2006), leading to a relatively greater number of large-bodied individuals and a shallower slope. In this study, across the globe, the slope was steeper than would be expected according to that reasoning. These steeper slopes could be due to a combination of functionally distinct trophic pathways affecting energy availability (Dinmore and Jennings, 2004; Maxwell and Jennings, 2006), greater human impacts affecting tropical reefs (Graham et al., 2005, Robinson et al., 2017)(see also Figure S6.1), or other factors affecting local variation in reef size spectra (Edgar, 1994; Rogers et al., 2014), and require further study.

A better understanding of the mechanisms underlying consistency and variability of slopes needs information on the spatial scales at which variability arises (Polishchuk and Blanchard, 2019). Investigation of different processes acting at local (e.g. sites) and larger spatial scales (e.g. ecoregions, global) should help to inform whether macroecological patterns are scale invariant (Rahbek, 2004; Connolly et al., 2017). A first step is to assess how much variation occurs at each scale. Here, we found that variation from the overall global size spectrum slope was explained about equally at both the ecoregion and site scales. Despite this scaleinvariance of slope, the drivers of this variation still probably differ with scale, and our work opens the door for further studies into the factors shaping the size spectrum slope at different scales. At the ecoregion scale, drivers of variation likely include commercial fishing practices (e.g. Blanchard et al., 2005), large-scale habitat loss (e.g. Morais et al., 2020b), changing climate (e.g. Robinson et al., 2019a b), and environmental forcing (e.g. Heenan et al., 2020). Potential drivers at the site scale include population processes (e.g. Barneche et al., 2014, 
2016), local community interactions, eutrophication (e.g. Turner, 2001), coastal pollution (e.g. Azzurro et al., 2010), and small-scale patchiness in fishing pressure related to human access (e.g. Robinson et al., 2017; Campbell et al., 2020).

Changes in size spectra slopes through time and space, have been used previously to assess changes in community and ecosystem health associated with the intensity of human activities (Shin et al., 2005; Dulvy et al., 2004, Wilson et al., 2010; Graham et al., 2005). Here, we used time-averaged size spectra on fished reefs, but future work on how size spectrum slopes vary with human activities (e.g. fishing and pollution) across time and space is needed. Reefs are also under pressure from the multifaceted effects of climate change (Graham et al., 2007). Integrative modelling, and empirical and mechanistic studies (e.g. Barneche et al., 2014; Morais et al., 2020a), are all needed to disentangle the combined and relative influences of multiple anthropogenic stressors when contrasted with natural ecological variation affecting size spectra. Advancing this research goal would assist development of predictive modelling tools for mapping changes on reefs, giving us a better idea of baseline reef size spectra and thus helping improve marine biodiversity policy and management (Stuart-Smith et al., 2017).

In order to use the size spectrum slope as an indicator of reef health across systems, we must first understand the theoretical baseline slope (Jennings and Blanchard, 2004), from which environmental, ecological and anthropogenic drivers of the remaining variation in slopes can be estimated. Our study highlights the importance of including invertebrates in reef size spectrum analyses for both the estimate of the baseline and for reducing variability in the slope estimates. When accounting for the invertebrates in the reef community, we show extremely high consistency in the size spectrum slope, supporting the generality of the biomass equivalence rule for reef communities at the global scale. 


\section{${ }_{297}$ Acknowledgements}

This research was supported by the Marine Biodiversity Hub, a collaborative partnership supported through funding from the Australian Government's National Environmental Science Program, and used the NCRIS-enabled Integrated Marine Observing System (IMOS) infrastructure for database support and storage. This research was also made possible by funding of the Australian Research Council (ARC), and the data from the Reef Life Survey Foundation. The authors also thank data support from Antonia Cooper, Just Berkhout, Diego Barneche, Scott Ling, Ella Clausius and Elizabeth Oh.

\section{References}

John L. Ackerman and David R. Bellwood. Reef fish assemblages: A re-evaluation using enclosed rotenone stations. Marine Ecology Progress Series, 206(1954):227-237, 2000. doi: 10.3354/meps206227.

John L. Ackerman, David R. Bellwood, and James H. Brown. The contribution of small individuals to density-body size relationships: Examination of energetic equivalence in reef fishes. Oecologia, 139(4):568-571, 2004. doi: 10.1007/s00442-004-1536-0.

K. H. Andersen and J. E. Beyer. Asymptotic size determines species abundance in the marine size spectrum. American Naturalist, 168(1):54-61, 2006. doi: 10.1086/504849.

Ken H. Andersen. Fish ecology, evolution, and exploitation: a new theoretical synthesis. Princeton University Press, 2019.

J.A. Anticamara, R. Watson, A. Gelchu, and D. Pauly. Global fishing effort (1950-2010): Trends, gaps, and implications. Fisheries Research, 107(1-3):131-136, January 2011. ISSN 01657836. doi: 10.1016/j.fishres.2010.10.016. URL https://linkinghub.elsevier.com/ retrieve/pii/S0165783610002754. 
Ernesto Azzurro, Marco Matiddi, Emanuela Fanelli, Paolo Guidetti, Gabriele La Mesa, Alfonso Scarpato, and Victor Axiak. Sewage pollution impact on Mediterranean rockyreef fish assemblages. Marine Environmental Research, 69(5):390-397, June 2010. ISSN 01411136. doi: 10.1016/j.marenvres.2010.01.006. URL https://linkinghub.elsevier. com/retrieve/pii/S0141113610000292.

D. R. Barneche, M. Kulbicki, S. R. Floeter, Alan M. Friedlander, J. Maina, and Andrew P. Allen. Scaling metabolism from individuals to reef-fish communities at broad spatial scales. Ecology Letters, 17(9):1067-1076, 2014. ISSN 1461-023X. doi: 10.1111/ele.12309.

D. R. Barneche, M. Kulbicki, S. R. Floeter, Alan M. Friedlander, and Andrew P. Allen. Energetic and ecological constraints on population density of reef fishes. Proceedings of the Royal Society B: Biological Sciences, 283(1823):20152186-20152186, 2016. ISSN 09628452. doi: 10.1098/rspb.2015.2186. URL http://rspb.royalsocietypublishing.org/ lookup/doi/10.1098/rspb.2015.2186.

Douglas Bates, Martin Mächler, Benjamin M. Bolker, and Steven C. Walker. Fitting Linear Mixed-Effects Models Using lme4. Journal of Statistical software, 67(1), 2015. doi: 10. 18637/jss.v067.i01.

Tim M. Blackburn and Kevin J. Gaston. Animal body size distributions: patterns, mechanisms and implications. Trends in Ecology and Evolution, 9(12):471-474, 1994. doi: 10.1016/0169-5347(94)90311-5.

Julia L. Blanchard, Nicholas K. Dulvy, Simon Jennings, James R. Ellis, John K. Pinnegar, Alex Tidd, and Laurence T. Kell. Do climate and fishing influence size-based indicators of Celtic Sea fish community structure? ICES Journal of Marine Science, 62:405-411, 2005. doi: 10.1016/j.icesjms.2005.01.006. Issue: 3.

Julia L. Blanchard, Ryan F. Heneghan, Jason D. Everett, Rowan Trebilco, and Anthony J. Richardson. From Bacteria to Whales: Using Functional Size Spectra to Model Marine 
Ecosystems. Trends in Ecology and Evolution, 32(3):174-186, 2017. doi: 10.1016/j.tree. 2016.12.003. URL http://dx.doi.org/10.1016/j.tree.2016.12.003. Publisher: Elsevier Ltd.

James H. Brown and James F. Gillooly. Ecological food webs: High-quality data facilitate theoretical unification. Proceedings of the National Academy of Sciences, 100(4):1467-1468, 2003.

James H. Brown, James F. Gillooly, Andrew P. Allen, Van M. Savage, and Geoffrey B. West. Toward a metabolic theory of ecology. Ecology, 85(7):1771-1789, 2004. ISSN 0012-9658. doi: $10.1890 / 03-9000$.

Stuart J. Campbell, Emily S. Darling, Shinta Pardede, Gabby Ahmadia, Sangeeta Mangubhai, Amkieltiela, Estradivari, and Eva Maire. Fishing restrictions and remoteness deliver conservation outcomes for Indonesia's coral reef fisheries. Conservation Letters, 13(2), March 2020. ISSN 1755-263X, 1755-263X. doi: 10.1111/conl.12698. URL https://onlinelibrary.wiley.com/doi/abs/10.1111/conl.12698.

Sean R. Connolly, Sally A. Keith, Robert K. Colwell, and Carsten Rahbek. Process, Mechanism, and Modeling in Macroecology. Trends in Ecology \&3 Evolution, 32(11): 835-844, November 2017. ISSN 01695347. doi: 10.1016/j.tree.2017.08.011. URL https: //linkinghub.elsevier.com/retrieve/pii/S016953471730215X.

Niels Daan, Henrik Gislason, John G Pope, and Jake C Rice. Changes in the North Sea fish community: Evidence of indirect effects of fishing? ICES Journal of Marine Science, 62 (2):177-188, 2005. doi: 10.1016/j.icesjms.2004.08.020.

John Damuth. Population density and body size in mammals. Nature, 290(23):699-700, 1981.

Marie Laure Delignette-Muller and Christophe Dutang. fitdistrplus: An R package for 
fitting distributions. Journal of Statistical Software, 64(4):1-34, 2015. URL http: //www.jstatsoft.org/v64/i04/.

T. A. Dinmore and S. Jennings. Predicting abundance-body mass relationships in benthic infaunal communities. Marine Ecology Progress Series, 276(1):289-292, 2004.

Mary K. Donovan, Alan M. Friedlander, Joey Lecky, Jean Baptiste Jouffray, Gareth J. Williams, Lisa M. Wedding, Larry B. Crowder, Ashley L. Erickson, Nicholas A. J. Graham, Jamison M. Gove, Carrie V. Kappel, Kendra Karr, John N. Kittinger, Albert V. Norström, Magnus Nyström, Kirsten L. L. Oleson, Kostantinos A. Stamoulis, Crow White, Ivor D. Williams, and Kimberly A. Selkoe. Combining fish and benthic communities into multiple regimes reveals complex reef dynamics. Scientific Reports, 8(1):1-11, 2018. doi: 10.1038/ s41598-018-35057-4.

N. K. Dulvy, N. V.C. Polunin, A. C. Mill, and N. A.J. Graham. Size structural change in lightly exploited coral reef fish communities: Evidence for weak indirect effects. Canadian Journal of Fisheries and Aquatic Sciences, 61(3):466-475, 2004. doi: 10.1139/f03-169.

Tyler D. Eddy, Joey R. Bernhardt, Julia L. Blanchard, William W.L. Cheung, Mathieu Colléter, Hubert du Pontavice, Elizabeth A. Fulton, Didier Gascuel, Kelly A. Kearney, Colleen M. Petrik, Tilla Roy, Ryan R. Rykaczewski, Rebecca Selden, Charles A. Stock, Colette C.C. Wabnitz, and Reg A. Watson. Energy Flow Through Marine Ecosystems: Confronting Transfer Efficiency. Trends in Ecology 83 Evolution, page S0169534720302573, October 2020. ISSN 01695347. doi: 10.1016/j.tree.2020.09.006. URL https://linkinghub.elsevier.com/retrieve/pii/S0169534720302573.

Graham J. Edgar. Observations on the size-structure of macrofaunal assemblages. Journal of Experimental Marine Biology and Ecology, 176(2):227-243, 1994. doi: 10.1016/ 0022-0981(94)90186-4.

Graham J. Edgar and Rick D. Stuart-Smith. Systematic global assessment of reef fish 
communities by the Reef Life Survey program. Scientific Data, 1:1-8, 2014. doi: 10.1038/sdata.2014.7.

Graham J. Edgar, Timothy J. Alexander, Jonathan S. Lefcheck, Amanda E. Bates, Stuart J. Kininmonth, Russell J. Thomson, Emmett Duffy, Mark J. Costello, and Rick D. StuartSmith. Abundance and local-scale processes contribute to multi-phyla gradients in global marine diversity. Science Advances, 3(10), 2017. doi: 10.1126/sciadv.1700419.

Andrew M. Edwards, James P.W. Robinson, Michael J. Plank, Julia K. Baum, and Julia L. Blanchard. Testing and recommending methods for fitting size spectra to data. Methods in Ecology and Evolution, 8(1):57-67, 2017. doi: 10.1111/2041-210X.12641.

Rainer Froese and D. Pauly. Fish Base, 2010. URL www.fishbase.se.

MS Ghilarov. Correlation between size and number of soil animals. Comptes Rendus (Doklady) de l'Academie des Sciences de l'URSS XLIII, 6:267-269, 1944.

Nicholas A. J. Graham, N. K. Dulvy, Simon Jennings, and N. V. C. Polunin. Size-spectra as indicators of the effects of fishing on coral reef fish assemblages. Coral Reefs, 24(1): 118-124, 2005. doi: 10.1007/s00338-004-0466-y.

Nicholas A. J. Graham, Shaun K. Wilson, Simon Jennings, Nicholas V. C. Polunin, Jan Robinson, Jude P. Bijoux, and Tim M. Daw. Lag effects in the impacts of mass coral bleaching on coral reef fish, fisheries, and ecosystems. Conservation Biology, 21(5):12911300, 2007. doi: 10.1111/j.1523-1739.2007.00754.x.

Adel Heenan, Gareth J Williams, and Ivor D Williams. Natural variation in coral reef trophic structure across environmental gradients. Frontiers in Ecology and the Environment, 18 (2):69-75, March 2020. ISSN 1540-9295, 1540-9309. doi: 10.1002/fee.2144. URL https : //onlinelibrary.wiley.com/doi/abs/10.1002/fee.2144.

Simon Jennings and Julia L. Blanchard. Fish abundance with no fishing: predictions based on macroecological theory. Journal of Animal Ecology, 73(4):632-642, July 2004. ISSN 
0021-8790, 1365-2656. doi: 10.1111/j.0021-8790.2004.00839.x. URL http://doi.wiley . com/10.1111/j.0021-8790.2004.00839.x.

Simon Jennings and Steve Mackinson. Abundance-body mass relationships in size-structured food webs. Ecology Letters, 6(11):971-974, 2003. doi: 10.1046/j.1461-0248.2003.00529.x.

Simon Jennings, John K. Pinnegar, Nicholas V. C. Polunin, and Trevor W. Boon. Weak cross-species relationships between body size and trophic level belie powerful size-based trophic structuring in fish communities. Journal of Animal Ecology, 70(6):934-944, 2001. ISSN 0021-8790. doi: 10.1046/j.0021-8790.2001.00552.x.

Stephen R Kerr and Lloyd Merlin Dickie. The biomass spectrum: a predator-prey theory of aquatic production. Columbia University Press, 2001.

Max Kleiber. Body size and metabolism. Hilgardia: A Journal of Agricultural Science, 6 (11):315-353, 1932. ISSN 9788578110796. doi: 10.1017/CBO9781107415324.004.

Raymond L Lindeman. The Trophic Dynamic of Ecology. Ecology, 23(4):399-417, 1942.

T A D Maxwell and Simon Jennings. Predicting abundance-body size relationships in functional and taxonomic subsets of food webs. Oecologia, 150(2):282-290, 2006. doi: $10.1007 / \mathrm{s} 00442-006-0520-2$.

Renato A. Morais and David R. Bellwood. Pelagic subsidies underpin fish productivity on a degraded coral reef. Current Biology, 29(9):1521-1527.e6, May 2019. ISSN 09609822.

doi: 10.1016/j.cub.2019.03.044. URL https://linkinghub.elsevier.com/retrieve/ pii/S0960982219303422.

Renato A. Morais, Sean R. Connolly, and David R. Bellwood. Human exploitation shapes productivity-biomass relationships on coral reefs. Global Change Biology, 26(3):12951305, March 2020a. ISSN 1354-1013, 1365-2486. doi: 10.1111/gcb.14941. URL https: //onlinelibrary.wiley.com/doi/abs/10.1111/gcb.14941. 
Renato A. Morais, Martial Depczynski, Christopher Fulton, Michael Marnane, Pauline Narvaez, Victor Huertas, Simon J. Brandl, and David R. Bellwood. Severe coral loss shifts energetic dynamics on a coral reef. Functional Ecology, 34(7):1507-1518, July 2020b. ISSN 0269-8463, 1365-2435. doi: 10.1111/1365-2435.13568.

P. J. Mumby. Fishing, Trophic Cascades, and the Process of Grazing on Coral Reefs. Science, 311(5757):98-101, January 2006. ISSN 0036-8075, 1095-9203. doi: 10.1126/science. 1121129. URL https://www.sciencemag.org/lookup/doi/10.1126/science.1121129.

Kirsty L. Nash and Nicholas A.J. Graham. Ecological indicators for coral reef fisheries management. Fish and Fisheries, 17(4):1029-1054, 2016. doi: 10.1111/faf.12157.

Sean Nee, Andrew F Read, Jeremy J D Greenwood, and Paul H Harvey. The relationship between abundance and body size in British birds. Nature, 351(May):312-313, 1991.

M E J Newman. Power laws, Pareto distributions and Zipf's law. Contemporary Physics, 46 (5):323-351, 2005. doi: 10.1080/00107510500052444.

M. L. D Palomares and D. Pauly. Sea Life Base, 2019. URL http://www . sealifebase.org/.

Owen L. Petchey and Andrea Belgrano. Body-size distributions and size-spectra: universal indicators of ecological status? Biology Letters, 6(4):434-437, August 2010. ISSN 17449561, 1744-957X. doi: 10.1098/rsbl.2010.0240. URL https://royalsocietypublishing. org/doi/10.1098/rsbl.2010.0240.

Leonard V. Polishchuk and Julia L. Blanchard. Uniting Discoveries of Abundance-Size Distributions from Soils and Seas. Trends in Ecology 6 Evolution, 34(1):2-5, January 2019. ISSN 01695347. doi: 10.1016/j.tree.2018.10.007. URL https://linkinghub.elsevier. com/retrieve/pii/S0169534718302647.

JG Pope and BJ Knights. Comparison of length distributions of combined catches of all demersal fishes in surveys in the North Sea and at Faroe Bank. In Multispecies approaches to fisheries management advice, volume 59, pages 116-118. 1982. 
R Core Team. R: A Language and Environment for Statistical Computing, 2020. URL https://www.R-project.org/

Carsten Rahbek. The role of spatial scale and the perception of large-scale species-richness patterns: Scale and species-richness patterns. Ecology Letters, 8(2):224-239, December 2004. ISSN 1461023X, 14610248. doi: 10.1111/j.1461-0248.2004.00701.x. URL http: //doi.wiley.com/10.1111/j.1461-0248.2004.00701.x.

Daniel C Reuman, Christian Mulder, Dave Raffaelli, and Joel E Cohen. Three allometric relations of population density to body mass: Theoretical integration and empirical tests in 149 food webs. Ecology Letters, 11(11):1216-1228, 2008. doi: 10.1111/j.1461-0248.2008. 01236.x.

RLS. Reef Life Survey, 2020. URL https://reeflifesurvey.com/.

James P. W. Robinson, Julia K. Baum, and Henrique Giacomini. Trophic roles determine coral reef fish community size structure. Canadian Journal of Fisheries and Aquatic Sciences, 73(4):496-505, 2016. doi: 10.1139/cjfas-2015-0178. URL http://www . nrcresearchpress.com/doi/10.1139/cjfas-2015-0178

James P. W. Robinson, Shaun K. Wilson, Simon Jennings, and Nicholas A. J. Graham. Thermal stress induces persistently altered coral reef fish assemblages. Global Change Biology, 25(8):2739-2750, August 2019a. ISSN 1354-1013, 1365-2486. doi: 10.1111/gcb. 14704. URL https://onlinelibrary.wiley.com/doi/abs/10.1111/gcb.14704.

James P. W. Robinson, Shaun K. Wilson, Jan Robinson, Calvin Gerry, Juliette Lucas, Cindy Assan, Rodney Govinden, Simon Jennings, and Nicholas A. J. Graham. Productive instability of coral reef fisheries after climate-driven regime shifts. Nature Ecology $\&$ Evolution, 3(2):183-190, February 2019b. ISSN 2397-334X. doi: 10.1038/s41559-018-0715-z. URL http://www.nature.com/articles/s41559-018-0715-z. 
James W. Robinson, Ivor D. Williams, Andrew M. Edwards, Jana McPherson, Lauren A. Yeager, Laurent Vigliola, Russell E. Brainard, and Julia K. Baum. Fishing degrades size structure of coral reef fish communities. Global Change Biology, 23(3):1009-1022, 2017. doi: $10.1111 /$ gcb.13482.

Alice Rogers, Julia L. Blanchard, and Peter J. Mumby. Vulnerability of coral reef fisheries to a loss of structural complexity. Current Biology, 24(9):1000-1005, 2014. ISSN 0960-9822. doi: 10.1016/j.cub.2014.03.026. URL http://dx.doi.org/10.1016/j.cub.2014.03.026. Publisher: Elsevier Ltd.

R. W. Sheldon, A. Prakash, and W. H. Sutcliffe. The size distribution of particles in the ocean. Limnology and Oceanography, 17(May):327-340, 1972. ISSN 00243590. doi: 10. 4319/lo.1972.17.3.0327.

R. W. Sheldon, W. H. Sutcliffe Jr., and M. a. Paranjape. Structure of Pelagic Food Chain and Relationship Between Plankton and Fish Production. Journal of the Fisheries Research Board of Canada, 34(12):2344-2353, 1977. ISSN TL381. doi: 10.1139/f77-314.

Yunne Jai Shin, Marie Joëlle Rochet, Simon Jennings, John G. Field, and Henrik Gislason. Using size-based indicators to evaluate the ecosystem effects of fishing. ICES Journal of Marine Science, 62(3):384-396, 2005. doi: 10.1016/j.icesjms.2005.01.004.

Mark D. Spalding, Helen E. Fox, Gerald R. Allen, Nick Davidson, Zach A. Ferdaña, Max Finlayson, Benjamin S. Halpern, Miguel A. Jorge, Al Lombana, Sara A. Lourie, Kirsten D. Martin, Edmund McManus, Jennifer Molnar, Cheri A. Recchia, and James Robertson. Marine Ecoregions of the World: A Bioregionalization of Coastal and Shelf Areas. BioScience, 57(7):573-583, 2007. doi: 10.1641/b570707.

William Gary Sprules, Lauren Emily Barth, and Henrique Giacomini. Surfing the biomass size spectrum: Some remarks on history, theory, and application. Canadian Journal of 
Fisheries and Aquatic Sciences, 73(4):477-495, 2016. ISSN 3497774413. doi: 10.1139/ cjfas-2015-0115.

Robert S. Steneck, David R. Bellwood, and Mark E. Hay. Herbivory in the marine realm. Current Biology, 27(11):R484-R489, 2017. doi: 10.1016/j.cub.2017.04.021. URL http: //dx.doi.org/10.1016/j.cub.2017.04.021. Publisher: Elsevier.

Rick D. Stuart-Smith, Graham J. Edgar, Neville S. Barrett, Amanda E. Bates, Susan C. Baker, Nicholas J. Bax, Mikel A. Becerro, Just Berkhout, Julia L. Blanchard, Daniel J. Brock, Graeme F. Clark, Antonia T. Cooper, Tom R. Davis, Paul B. Day, J. Emmett Duffy, Thomas H. Holmes, Steffan A. Howe, Alan Jordan, Stuart Kininmonth, Nathan A. Knott, Lefcheck S. Jonathan, Scott D. Ling, Amanda Parr, Elisabeth Strain, Sweatman Hugh, and Thomson Russell. Assessing national biodiversity trends for rocky and coral reefs through the integration of citizen science and scientific monitoring programs. BioScience, 67(2):134-146, 2017. doi: 10.1093/biosci/biw180.

Rowan Trebilco, Julia K. Baum, Anne K. Salomon, and Nicholas K. Dulvy. Ecosystem ecology: Size-based constraints on the pyramids of life. Trends in Ecology and Evolution, 28(7):423-431, 2013. ISSN 0169-5347. doi: 10.1016/j.tree.2013.03.008. URL http://dx. doi.org/10.1016/j.tree.2013.03.008. Publisher: Elsevier Ltd.

Rowan Trebilco, Nicholas K. Dulvy, Sean C. Anderson, and Anne K. Salomon. The paradox of inverted biomass pyramids in kelp forest fish communities. Proceedings of the Royal Society B: Biological Sciences, 283(1833), 2016. doi: 10.1098/rspb.2016.0816.

R. Eugene Turner. Some effects of eutrophication on pelagic and demersal marine food webs. In Nancy N. Rabalais and R. Eugene Turner, editors, Coastal and Estuarine Studies, volume 58, pages 371-398. American Geophysical Union, Washington, D. C., 2001. ISBN 978-0-87590-272-2. doi: 10.1029/CE058p0371. URL http://www.agu.org/books/ce/ v058/CE058p0371/CE058p0371.shtml. 
${ }_{541}$ Ethan P White, Brian J Enquist, and Jessica L Green. On estimating the exponent of power ${ }_{542}$ law frequency distributions. Ecology, 89(4):905-912, 2008.

${ }_{543}$ SK Wilson, R Fisher, MS Pratchett, NAJ Graham, NK Dulvy, RA Turner, A Cakacaka, and ${ }_{544} \quad$ NVC Polunin. Habitat degradation and fishing effects on the size structure of coral reef 545 fish communities. Ecological Applications, 20(2):442-451, 2010.

${ }_{546}$ Brian J. Zgliczynski and Stuart A. Sandin. Size-structural shifts reveal intensity of ex${ }_{547}$ ploitation in coral reef fisheries. Ecological Indicators, 73:411-421, February 2017. ISSN ${ }_{548}^{\square}$ 1470160X. doi: 10.1016/j.ecolind.2016.09.045. URL https://linkinghub.elsevier. $549 \quad$ com/retrieve/pii/S1470160X16305763. 

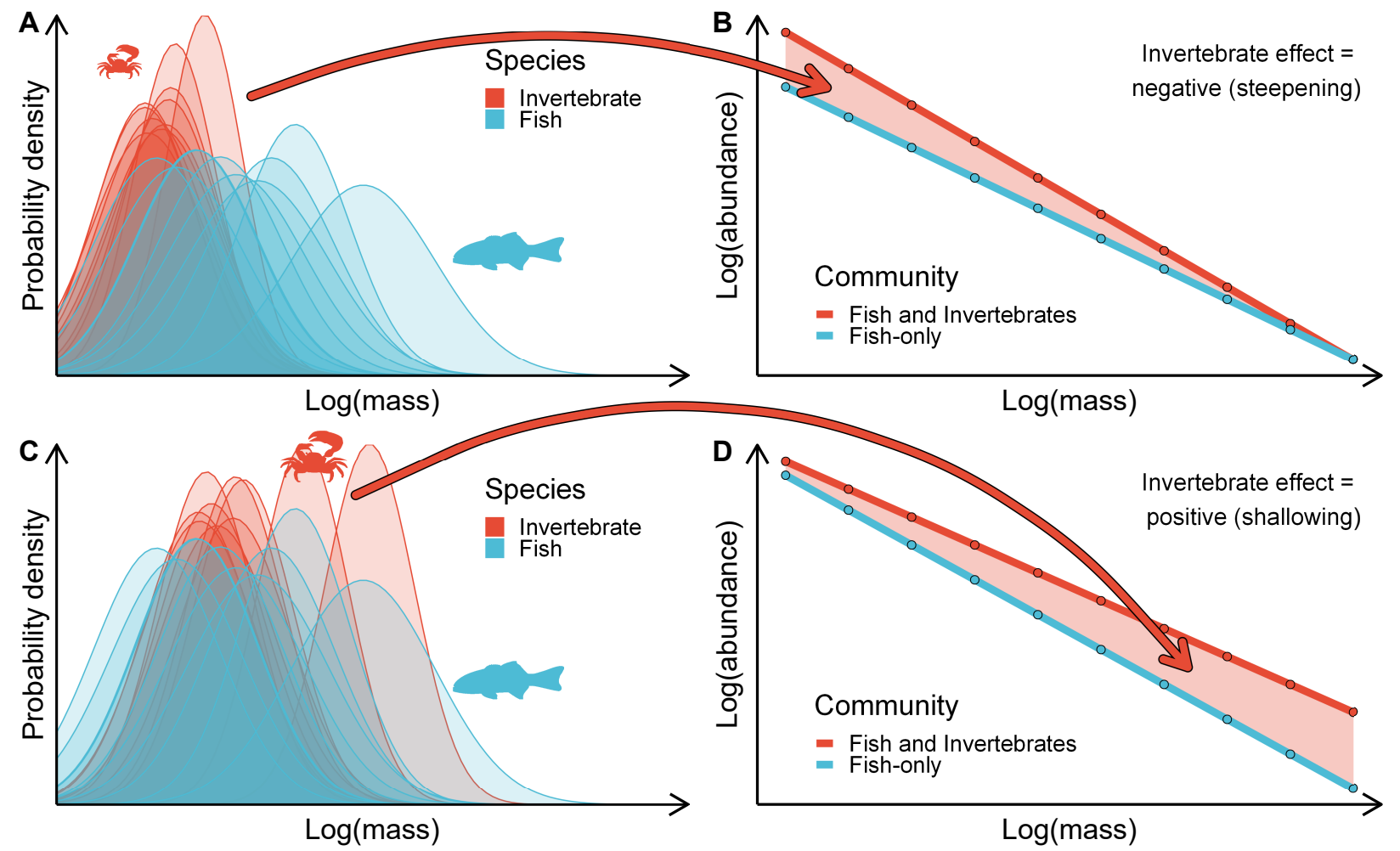

Figure 1: Hypothesized effect of including invertebrates in the size spectrum: 1) A steepening effect (A, B), and 2) a shallowing effect (C, D). The steepness of the size spectrum arises from the relative abundances of larger and smaller bodied individuals. If invertebrates have a steeper size spectrum slope (i.e. relatively fewer large-bodied individuals) compared to their co-located fish (A), we would expect the slope of the size spectrum of the combined community (fish and invertebrates) to be steeper than the slope of the fish only (B). A shallowing effect (D) would be expected if invertebrates have a relatively greater number of large-bodied individuals compared to the fish-only community (C). 


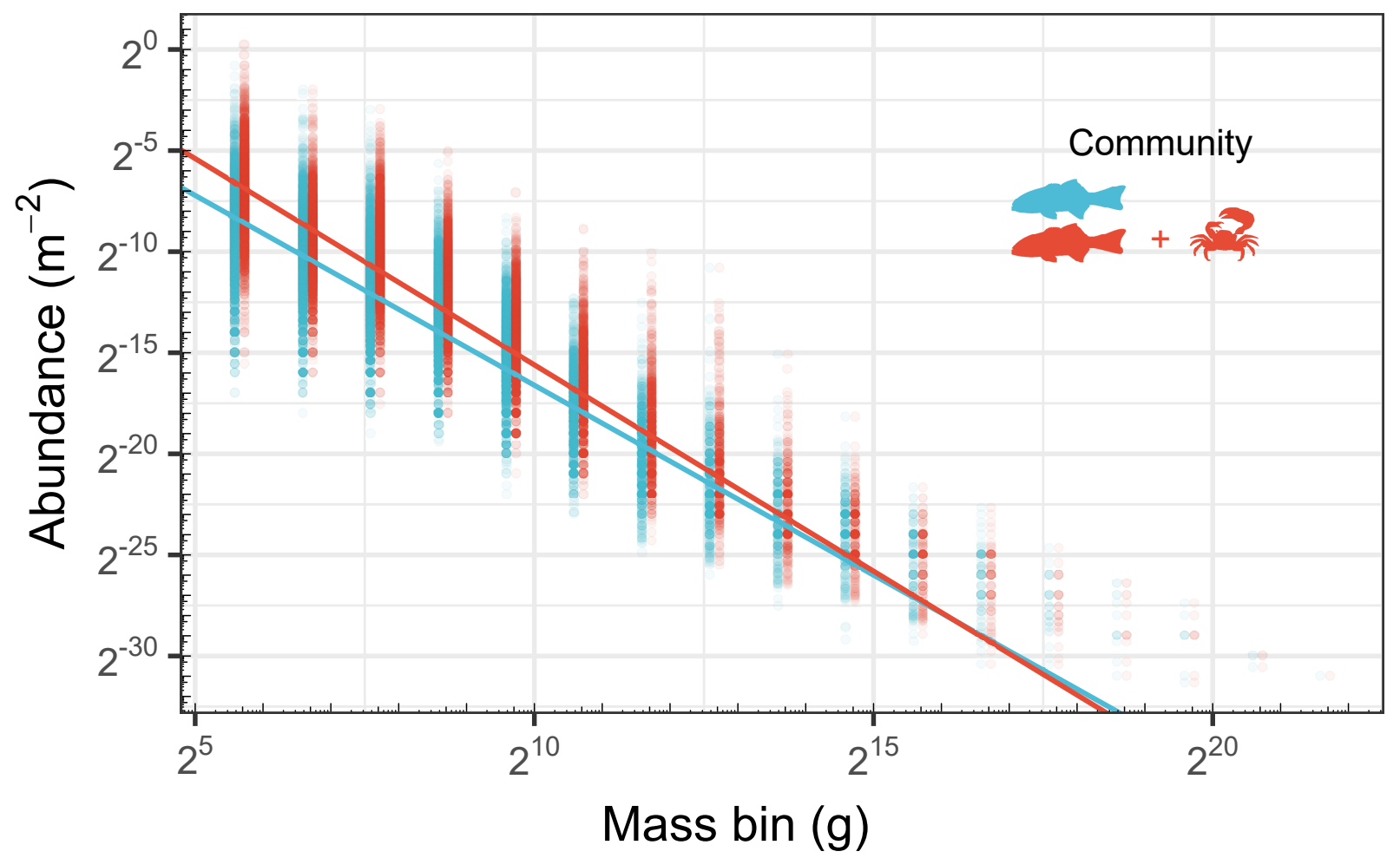

Figure 2: Invertebrates steepen the normalized abundance size spectrum. Separate normalized abundance size spectra are shown for the fish-only and combined (fish and invertebrate) communities, with solid lines representing fits from linear mixed effects models for the global data ("Site" nested within "Ecoregion" as random effects). Fish-only slope $=-1.88 \pm 0.06$, combined slope $=-2.04 \pm 0.06$. Points have been offset on the $\mathrm{x}$-axis for clarity. 


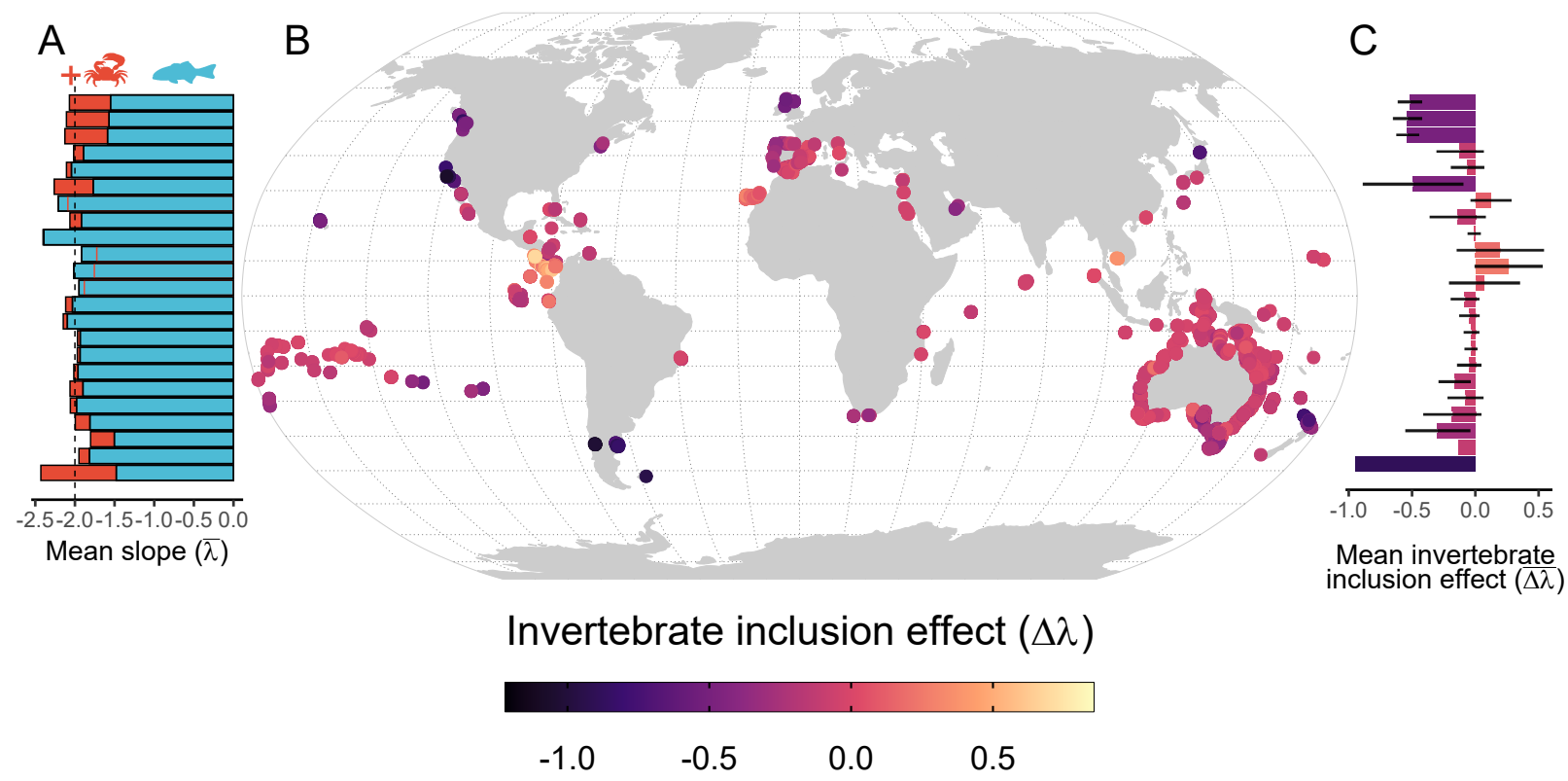

Figure 3: The inclusion of invertebrates results in a consistent community size spectrum slope of $\sim-2$. (A) The size spectrum slope for fish-only communities (blue) and when including invertebrates (orange) - orange vertical lines have been used to indicate the top of the orange bar when obscured. (B) A map of the invertebrate inclusion effect $(\Delta \lambda)$ across the globe. (C) The latitudinal variation of the 'invertebrate inclusion effect' $(\Delta \lambda)$. The steepening effect when including invertebrates is greatest at high latitudes. Each bar in A and C represents the mean over $5^{\circ}$ of latitude. Error bars in $\mathrm{C}$ represent the $95 \%$ confidence intervals, and missing error bars represent insufficient data. 


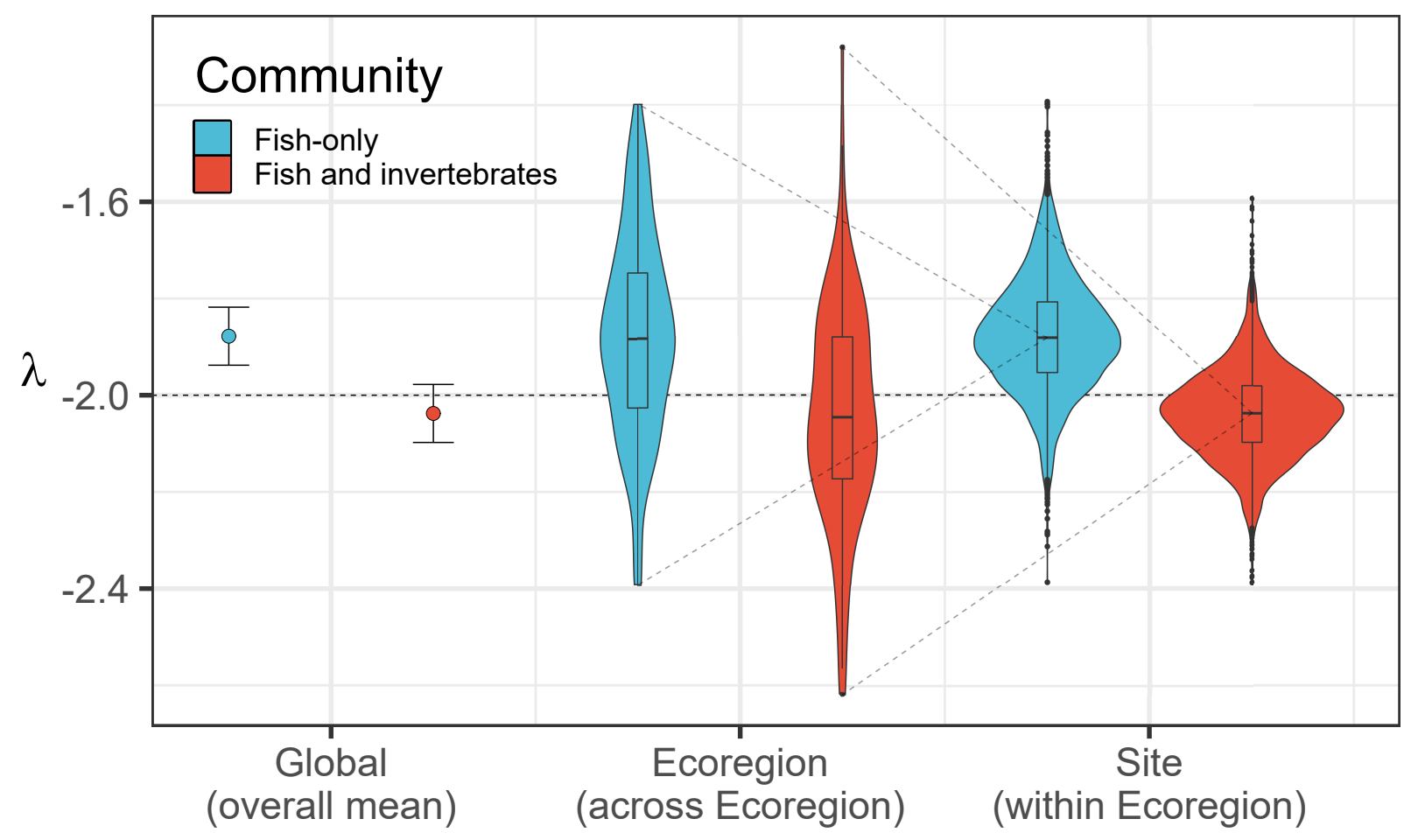

Figure 4: The contribution of spatial scale to abundance size spectra slope estimates. "Ecoregion" refers to the variation among ecoregions globally in the linear mixed effects model and "Site" refers to the variation among individual reef sites within ecoregions. Dotted lines between the violins are added to emphasize that the variation at the site level represents the added variation after accounting for the variation at the ecoregion level. A horizontal dotted line at -2 is added to highlight the slope in previous studies based on pelagic studies. 